\title{
OLD AGE HOMES: ARE THEY ACCEPTABLE TO PAKISTANI GERIATRIC POPULATION? RESULTS OF A SURVEY OF ELDERLY OUTPATIENTS VISITING TEACHING HOSPITALS IN KARACHI, PAKISTAN
}

\author{
Waris Qidwai ${ }^{1}$, Imdad Ali Khushk ${ }^{2}$, Fizzah Farooq ${ }^{3}$, Muhammad Yusuf Hafiz ${ }^{4}$, Kashmira Nanji \\ ${ }^{1}$ Professor and Chairman, Family Medicine Department, Aga Khan University Karachi Pakistan \\ ${ }^{2}$ Pakistan Medical \& Dental Council (PM\&DC) - Islamabad \\ ${ }^{3}$ Medical College Dow University of Health Sciences Karachi Pakistan \\ ${ }^{4}$ Medical College Dow University of Health Sciences Karachi Pakistan \\ Corresponding Author: Kashmira Nanji, Contact: (9221) 34864868, Email: kashmira.nanji@aku.edu
}

\begin{abstract}
Background: Worldwide, some one million people pass the sixty year old threshold every month (Ageing, WHO). Between 2010 and 2050, the number of older people in less developed countries is projected to increase.

Methods: Cross-sectional study conducted in Outpatient clinics (OPD) of two hospitals in Karachi from April to May 2013. Elderly (>60 years of age) visiting the clinics were consecutively recruited. 477 elderly were approached and a pretested, structured questionnaire was used to obtain information. Data was analyzed using SPSS version 19 and Pearson chi-square test was used to identify the factors related to choosing of "Old Age Homes".

Results: A total of 400 participants were selected. Fifty-five percent of the elderly were in between 60 to 65 years of age and majority was males 54.8 percent. Elderly were aware of the presence of "Old Age Homes" in Pakistan, however only 7 percent choose to live in there. The main reason was found to be that the elderly did not want to go away from their families and loved ones.

Conclusion: In conclusion, majority of the participants felt insecure to live in a home with strangers. However, "Old Age Homes" were preferred choice for those with chronic diseases or those living alone. Media should initiate public education programs to reduce social stigmas in seeking alternate long-term care services outside of the family.
\end{abstract}

Keywords: Elderly, old age homes, pakistan

\section{Introduction}

Population ageing is the most significant result of the process known as demographic transition. The phenomenon of population ageing is becoming a major concern for the policy makers all over the world, for both developed and developing countries, during last two decades (1). However, it has varied implications for underdeveloped, developing and developed countries. We soon will have more old people than children and more people at extreme old age than ever before (2). Therefore to provide better care to elderly "Old Age Homes" are gaining importance with every passing day. The cultures and traditions also play an important role in shaping up the norms of the society. In Saudi Arabia, older people prefer living with their families rather than institutions. So, there is no concept of "Old Age Homes" in Saudi Arabia (3). Indian culture, like many other Asian cultures, emphasized filial piety and parents are to be honored as gods $(4,5)$. Moreover, leaving parents in "Old Age Homes" raises cultural issue questions, especially in developing countries. In the past years, there was no concept of "Old Age Homes" in
Pakistani society, because the joint family system was prevailing and the head of the family was the sole bread earner, but as times have changed and the life has become fast and stressful, people do not have time for their families especially to take care of the elderly (6). This is also evident by the fact that in 2006, there were only three "Old Age Homes" in Karachi but now the official number has gone up to six.7,8 While people may hold firm to the belief that 'abandoning' a parent is against social and religious norms in Pakistan, there is no denying that such places for elderly to live offer advantages, in a rapidly changing society and its priorities. The elderly can get a chance to socialize with people of the same age and it can have positive impact on their overall health bit particularly on mental health (4). A survey conducted by ASEAN (Association of Southeast Asian Nations), has concluded that most of the support for the elderly in Asian countries comes from their children and/or grandchildren.4 However, it is expected that family nucleation would create voids in the traditional joint family systems that have persisted in Asia. All these aspects lead to a challenging situation for 
youth, to decide to let their old family members to live in "Old Age Homes".

Worldwide studies have been carried out on prevalence and evaluation of quality of services provided in the "Old Age Homes", however, limited evidence is available regarding the perceptions of elderly regarding "Old Age Homes" in Pakistan. Therefore, the aim of this study was to explore the perceptions of elderly regarding "Old Age Homes".

\section{Methodology}

A cross-sectional study was carried out at outpatient department (OPD) clinics of two tertiary care hospitals in Karachi, Pakistan during April to May 2013. These OPD clinics were chosen to obtain a diverse sample belonging to various socio-economic strata. Patients more than 60 years of age, visiting the outpatient's clinics of study hospitals, were included in the study. However patients suffering from serious co-morbid conditions like cancer, advanced heart failure or end stage renal/liver failure etc. were excluded. A total of 480 adult patients were consecutively approached to take part in this study, out of which 400 (83 percent) agreed to participate and were interviewed. Participants were interviewed through a pre-tested and structured questionnaire comprising of two sections; socio-demographic profile, perceptions and reasons for opting/ not opting to live in "Old Age Homes". The English version of the questionnaire was translated into Urdu language and was back translated in English to check for consistency and any discrepancies found were removed. Pretesting of the Urdu version was done on 20 participants that is approximately 5 percent of the total sample size. The final questionnaire was shared with experts in the field of family medicine to obtain their suggestions for improvement.

Two medical graduates were recruited on voluntary basis and were trained for data collection. The data collection was done when the patients came out of the consultation room (exit interview). Written Informed Consent was obtained from all participants after explaining them about the study protocol. All study personnel were trained in procedures for maintaining confidentiality of the information obtained. No personal identifiers were used in any report or publication arising from this study. The study was conducted in accordance with the 'Ethical principles for medical research involving human subjects' of Helsinki Declaration. The study was reviewed and approved by the Family Medicine research committee at Aga Khan University. The data was entered in Epi Data version 3.1 and analyzed in Statistical Package for Social Sciences 19.0 (SPSS, Inc., Chicago, IL, USA). Descriptive statistics included mean ( \pm standard deviation) for continuous and proportion for categorical variables were computed. Pearson chisquare test was used to identify the reasons related with preference of living in an Old Age Home. P value of less than 0.05 is considered as statistically significant.

\section{Results}

In this study, 477 elderly were approached, out of which 400 consented to be part of the study, yielding a response rate of $400 / 477=83.8$ percent. Missing information was handled through mean imputation. The socio-demographic characteristic of the participants is given in Table 1. About 55 percent of the participants were between $60-65$ years of age and 25 percent were aged more than 70 years. There was preponderance of male participants (55 percent) in the study. Out of the total 400 participants, 59.5 percent were living in a joint family system while about 4 percent were living alone. About 56 percent of the elderly participants were aware of the presence of "Old Age Homes" and $7.5 \%$ of the participants were willing to live in old age homes.

Table 1: Sociodemographic characteristics of the study participants $(n=400)$

\begin{tabular}{|l|l|l|}
\hline Variables & $\mathbf{n}$ & $\mathbf{\%}$ \\
\hline Gender & \multicolumn{2}{|l|}{} \\
\hline Male & 219 & 55 \\
\hline Female & 181 & 45.3 \\
\hline Age & \multicolumn{2}{|l|}{} \\
\hline 60-65 years & 221 & 55.3 \\
\hline 65 to 70 years & 79 & 19.8 \\
\hline More than 70 years & 100 & 25 \\
\hline Chronic Disease & & \\
\hline Yes & 197 & 49.3 \\
\hline No & 203 & 50.8 \\
\hline Family System & & \\
\hline Nuclear family & 239 & 59.7 \\
\hline Extended family & 144 & 36.0 \\
\hline Alone & 17 & 4.3 \\
\hline Housing Structure & \multicolumn{2}{|l|}{} \\
\hline Owned & 237 & 59.3 \\
\hline Rented & 163 & 40.7 \\
\hline $\begin{array}{l}\text { Mean no of people } \\
\text { living in house }\end{array}$ & $6.34+\ldots 3.72 *$ \\
\hline Willingness to live in old age homes \\
\hline Yes & 30 & 7.5 \\
\hline No & 370 & 92.5 \\
\hline Awareness regarding old age homes \\
\hline Yes & 224 & 56 \\
\hline No & 176 & 44 \\
\hline
\end{tabular}

Table 2 presents the perceptions of elderly about living in "Old Age Homes". Majority of the elderly who are willing to live in "Old Age Homes" responded that the main reason for opting to live in there is because they would be in constant supervision and proper care will be provided. This was also confirmed when 46 percent of the elderly responded that since their health is deteriorating, one day their family would no longer be able to take care of them at home. On the other hand, those who were not 
willing to live in old age homes, 85 percent amongst them, responded that they do not wish to be away from their family. Moreover, over two third of the elderly believed that they will feel disrespected, if their children will send them to "Old Age Homes".

Table 2: Perceptions of elderly regarding living in old age homes

\begin{tabular}{|l|c|c|}
\hline Statements & $\mathbf{n}$ & $\mathbf{\%}$ \\
\hline *Willing to live in old age homes (n=30) & & \\
\hline Difficult to live with your children due to differences in the values and lifestyles & 4 & 13.3 \\
\hline $\begin{array}{l}\text { Health is deteriorating - one day your family would no longer be able to take care of } \\
\text { you at home }\end{array}$ & 14 & 46.6 \\
\hline Under better and constant supervision at Old Age Homes & 17 & 56.6 \\
\hline Will get a chance to make new friends & 2 & 6.6 \\
\hline *Not willing to live in old age homes (n=370) & 338 & 91.3 \\
\hline Do not wish to be away from family & 84 & 22.7 \\
\hline Dread being ignored by staff at the old age & 68 & 18.3 \\
\hline Fear being treated as a disease and not a person & 21 & 56.7 \\
\hline Do not think you can make friends with people around you in the old age home & 51 & 13.7 \\
\hline gDo not think a paid and trained staff can tend to you just as well as a family member & 22 & 5.9 \\
\hline Cannot afford the Old Age Home & 52 & 14.0 \\
\hline It will give you a sense of parental failure & 158 & 42.7 \\
\hline Will feel disrespected & 73 & 19.7 \\
\hline Nursing homes are a dumping place for the elderly where they idle till death & 11 & 2.9 \\
\hline $\begin{array}{l}\text { The restrictive visiting hours to have guests or limitations on going out are } \\
\text { unacceptable }\end{array}$ & 19 & 5.1 \\
\hline Old Age Homes are merely profit making organizations & \\
\hline
\end{tabular}

Redundant categories have been removed *Multiple response questions sum cannot be $100 \%$

Table 3 shows that presence of chronic diseases $(P=$ $0.04)$ and family system $(P=<0.001)$ was associated with the perception of elderly regarding "Old Age Homes". However, age $(P=0.81)$ and gender $(P=0.82)$ was not statistically significant.

Table 3: Factors Associated with perception regarding old age home

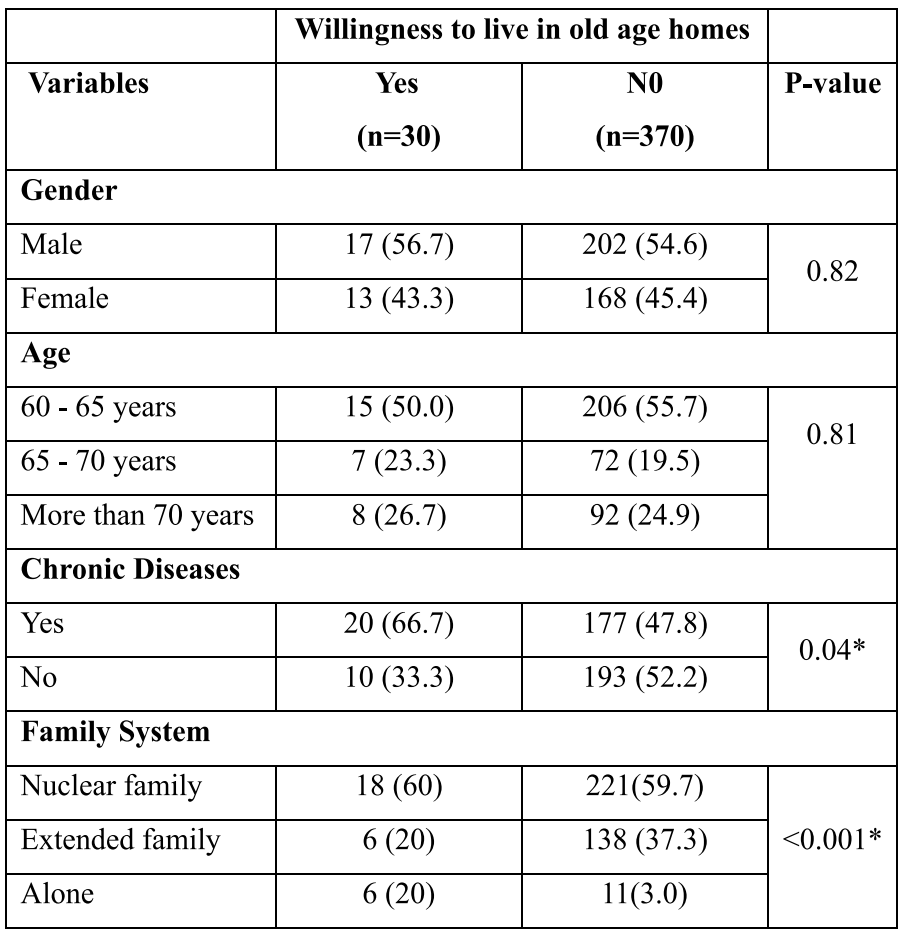

\section{Discussion}

This is the first cross sectional study, to explore the perceptions of elderly (>60 years) regarding living in "Old Age Homes", in Karachi-Pakistan and reasons for their decision. As human beings grow older, they go through different phases or stages of life. Each phase comes with different responsibilities and expectations. Ageing comes with many challenges. The loss of independence is one potential part of the process, as are diminished physical ability and health. Research on "Old Age Homes" in Pakistan is still in its infancy, because of the traditional joint family system prevailing in the country.

As expected, results of the current study shows that majority of the elderly (93 percent), don't wish to live in "Old Age Homes" and only 56 percent of the participants were aware of their existence in Pakistan, because of lack of media reach in the country, rural areas in particular 8. These figures are consistent with the proportion of elderly living in "Old Age Homes" in Canada, where according to the census in 2001, only 7.9 percent of the total elderly people live in "Old Age Homes". In USA, slightly over 5 percent live in "Old Age Homes" but this number increases to 24 percent among older adults (over the age of 90) (4). The participants responded that the main reason for not willing to live in "Old Age Homes" is because they don't want to be away from their family, since the traditional family system in South Asia is joint family system $(7,8)$. In Asian families, elderly are considered to be a source of inspiration and are looked upon as a primary source of guidance. In return, they are provided with care and support from the family members (9). Since parents raise their children in the best way they can, they expect them to not only take care of them in their old stage but even give them quality time, affection and love (10). A study conducted on residents of four "Old Age Homes", concluded that the inmates (elderly) believed that although living in an "Old Age Homes" is safe but it is very lonely without the family and the loved ones (11). Out of those who preferred to live in "Old Age Homes", 17 percent of them perceived that they can be taken care in a better manner by trained nurses and staff. Since, chronically ill and bed bound patient need continuous services from a care giver, only trained health care personnel can provide them timely care on daily basis (12). Elderly people need a constant person to talk to, share feelings with and fed, in era of modernization nuclear family is breaking down and family relations are at risk. It has been shown that stressful family relationships and lack of family care precipitates poor psychological well-being for the elderly (13). The current study showed that chronic illness was related to participants' perception of living in "Old Age Homes". The elderly believed that their health was deteriorating to such a level that a time will come when soon their children won't be able to take care of them so "Old Age Homes" would be the ultimate option $(14,15)$. One of the possible reasons for this could be due to the fact that society and its norms have changed. Women 
who used to be confined to their duties at home, now due to the rising inflation and cost of living, are compelled to leave their homes, earn and contribute to the family expenses. 15, 16 Women's labor force participation has reduced the number of care givers available to care for their elderly relatives $(16,17)$. The study provided evidence to support association between living alone and preference to live in "Old Age Homes". Since living alone made them feel left out and lack of social circle and no family made them dread for death, so in "Old Age Homes", they think that they will be able to make new friends and have someone to talk and share feelings with of same age group $(18,20)$. No other associations between gender and age group on choosing to live in "Old Age Homes" were statistically significant in the current study.

Efforts at individual and family level:

Efforts must be made to inculcate cultural values and traditional practice of providing support to elders. Families must care for the elderly; help them financially, give them love, support \& respect. Thus, the rebirth of "familism" may be the option to prevent break ground of joint family system.

Efforts by government:

In developing countries like Pakistan, government needs to set up incentives for development of "Old Age Homes", with improved facilities so old age people who do not have any one to take care, are not left on streets. Proper treatment can even decrease mortality rate of heirless deaths which occur on roadside. The government should also assess the facilities and quality of services provided by the "Old Age Homes" to further improve their facilities and increase the satisfaction levels of elderly.

Efforts by Media:

The wrong impression which people have of being rebuked and ill-treated in "Old Age Homes" can be eliminated by proper media campaign. Rural areas are deprived of awareness of "Old Age Homes", informative documentaries in local language will spread the true meaning and value of "Old Age Homes" in cases where families cannot support their elders.

\section{Conclusion}

This study concluded that although elderly participants were aware of the presence of "Old Age Homes" in Pakistan, majority didn't feel secure in leaving their home and living in a home with strangers. However, "Old Age Homes" were a preferred choice for those with chronic diseases or those living alone. Media should initiate public education programs to reduce social stigmas in seeking alternate long-term care services outside of the family.

\section{Competing interests}

The authors declare that they have no competing interests.

\section{Acknowledgements}

We are thankful to all the nursing and administrative staffs of the clinics.

\section{References}

1 Tan PC. Implications of changing family structures on old-age support in the ESCAP region. Asia Pac Popul J. 1992; 7:49-66.

2 Baen H, Dalgard OS, Johansen R, Nord E. A randomized controlled trial of a senior centre group programme for increasing social support and preventing depression in elderly people living at home in Norway. BMC geriatrics. 2012;12:20.

3 Abolfotouh MA, Daffallah AA, Khan MY, Khattab MS, Abdulmoneim I. Psychosocial assessment of geriatric subjects in Abha City, Saudi Arabia. East Mediterr Health J. 2001;7:481-491.

4 Knodel J, Debavalya N. Social and economic support systems for the elderly in Asia: an introduction. Asia Pac Popul J. 1992;7:5.

Litwin $\mathrm{H}$, Shiovitz-Ezra S. The association between activity and wellbeing in later life: what really matters? Ageing and Society. 2006;26(2):225-242.

6 Chan HYL, Pang S. Readiness of Chinese frail old age home residents towards end of life care decision making. J Clin Nurs. 2011;20:14541461.

7 Itrat A, Taqui AM, Qazi F, Qidwai W. Family systems: perceptions of elderly patients and their attendents presenting at a university hospital in Karachi, Pakistan. J Pak Med Assoc. 2007;57(2):106.

8 Taqui AM, Itrat A, Qidwai W, Qadri Z. Depression in the elderly: Does family system play a role? A cross-sectional study. BMC psychiatry. 2007;7:57.

9 Saraceno C. Social inequalities in facing old-age dependency: a bi-generational perspective. J Eur Soc Policy. 2010;20:32-44.

10 Barnhart M, Peaaloza L. Who Are You Calling Old? Negotiating Old Age Identity in the Elderly Consumption Ensemble. J Consum Res. 2013;39:1133-1153.

11 Fange A, Ivanoff SD. The home is the hub of health in very old age: Findings from the ENABLE-AGE Project. Arch Gerontol Geriatr. 2009;48:340-345.

12 Priebe S, Saidi M, Want A, Mangalore R, Knapp $M$. Housing services for people with mental disorders in England: patient characteristics, care provision and costs. Soc Psych Psych Epid. 2009;44:805-814.

13 Huang C-Q, Dong B-R, Lu Z-C, Yue J-R, Liu Q$X$. Chronic diseases and risk for depression in old age: a meta-analysis of published literature. Ageing Res Rev. 2010;9:131-141.

14 Brajkovia L, Godan A, Godan L. Quality of life after stroke in old age: comparison of persons living in nursing home and those living in their own home. Croat Med J. 2009;50:182-188. 
15 Lo RS, Kwan BHF, Lau KPK, Kwan CWM, Lam LM, Woo J. The needs, current knowledge, and attitudes of care staff toward the implementation of palliative care in old age homes. American J. of Hospice and Palliat. Medicine. 2010;27:266271.

16 Luppa M, Luck T, Weyerer S, Kallnig $\mathrm{H}-\mathrm{H}$, Brahler E, Riedel-Heller SG. Prediction of institutionalization in the elderly. A systematic review. Age and ageing. 2010;39:31-38.

17 Oliveira SE, Hohendorff JV, Muller JdL, Bandeira DR, Koller SH, Fleck MP. et al. Associations between self-perceived quality of life and socio-demographic, psychosocial, and health variables in a group of elderly. Cadernos de Saude Publica. 2013;29:1437-1448.

18 Dubey A, Bhasin S, Gupta N, Sharma N. A Study of Elderly Living in Old Age Home and Within Family Set-up in Jammu. Stud. Home Comm. Sci. 2011;5:93-98.

19 Fahey T, Montgomery AA, Barnes J, Protheroe J. Quality of care for elderly residents in nursing homes and elderly people living at home: controlled observational study. Bmj. 2003;326:580.

20 Kassa $H$, Murugan $R$, Zewdu F, Hailu M, Woldeyohannes D. Assessment of knowledge, attitude and practice and associated factors towards palliative care among nurses working in selected hospitals, Addis Ababa, Ethiopia. BMC palliative care. 2014;13: 